Journal of Advanced Research in Applied

Sciences and Engineering Technology

Journal homepage: www.akademiabaru.com/araset.html ISSN: 2462-1943

\title{
Design of Multipurpose Hydraulic Tool for Door Installation
}

\author{
Asnizah Sahekhaini ${ }^{1,}{ }^{*}$, Norhayati Ibrahim ${ }^{1}$, Bibie Sara Salleh ${ }^{1}$, Salhana Sahidin@Salehudin ${ }^{1}$, \\ Aminudin $\mathrm{Abu}^{2}$ \\ Politeknik Sultan Salahuddin Abdul Aziz Shah, Shah Alam, Persiaran Usahawan, Seksyen U1, 40150 Shah Alam, Selangor, Malaysia \\ Malaysia-Japan International Institute of Technology, Universiti Teknologi Malaysia, Jalan Sultan Yahya Petra, 54100 Kuala Lumpur, Malaysia
}

\section{ABSTRACT}

The development of multipurpose hydraulic door installation tool is aimed to overcome the problem during the door installation process. Normally, the door installation needs a lot of workforce starting from transporting the door to the installation site, adjusting the door clearance at the bottom part and setting the door in static with $90^{\circ}$ position for mounting the hinge on the door frame. The design of the multipurpose hydraulic door installation tool is portable, adjustable using simple hydraulic jack and capable to transporting various types and sizes of door, i.e. wooden, plastic and steel. Through this innovation the door installation can be done individually, easier, saving the time and cost. In addition, the production cost is very reasonable and potential to use widely in the construction industry and personal usage.

\section{Keywords:}

Multipurpose hydraulic; door

installation; hydraulic jack

Copyright $@ 2020$ PENERBIT AKADEMIA BARU - All rights reserved

\section{Introduction}

Under the circumstances surrounding Malaysia, consumers want a product to facilitate innovation with existing products or the creation of something that has never been created. Prior to technological developments, communities in Asia, especially in Malaysia, often used manual methods to do any work. Since technology has grown rapidly, there are new innovations introduced to ease the load and meet demand customers. In this modern era, there are still many communities working on building construction. In the building construction there are various processes involved. Installation of doors is one of the processes during the construction. A door is a moving mechanism used to block off and allow access to, an entrance to or within an enclosed space, such as a building, room or vehicle [1]. Doors normally consist of one or two solid panels, with or without windows that swing using hinges horizontally [2]. These hinges are attached to the door's edge but there are also doors that slide, fold or spin.

Installing door is complicated process requiring many installation steps. A method of installing a door comprising the steps of; check the rough opening, level the floor, attach temporary blocks to

\section{*Corresponding author asnizah@psa.edu.my}


the jump, use block to level jamb bottoms, nail the blocks to the wall, check gap at door stops and shim behind hinges [1]. An improperly installed door can bind, swing open by itself or rattle in the breeze when closed and it annoying. The most critical step of any door or gate installation is to level bottom of each floor at the proper height and to hold a workpiece steady [2]. Normally, temporary blocks are attached to both sides of the jamb to hold the doorjamb flush with the drywall before permanently fastening it. The problems associated with this are as follows:

i) Inconsistency in door fitment calls for the development of a systematic hanging fixture adjustment scheme [3]

ii) The capability of correcting the gap deviations is not understood [2]. Due to this, the faults cannot be located for corrections

iii) Hammering operation is done for door fitting which leads to bending of hinges [4]

iv) The correct procedure is not available for door fixture adjustment [5]

The installation process requires two or more workforces starting from carry the door, adjust the door clearance at the bottom part at the proper height and hold a door in steady positions, adjusted when necessary and bolted with hinges on the door frame. Adjustment can include twisting and bending of the door or by moving the hinges. This process is time-consuming and less accurate. There are various types of the door in the market, such as wood, steel and glass. The delivering and installing door must be done carefully to prevent broken glass door.

At present, there are no standard tools available in the market for door installation purposes. Therefore, this project has been carried out to create innovative multipurpose tool for door logistic, to secure mounting point and as a fixing during installation with increased the accuracy, reliability and durability. The process of door installation can be done individually, user friendly, reduce the working time and costs by allowing quick set-up. Also allows for a higher degree of workforce safety by reducing the concentration and effort required to hold the piece steady. The production cost is very reasonable and potential to use widely in the construction industry, entrepreneur, contractor and personal usage.

\section{Methodology}

The project design approached by considering all possible alternatives for the project and modelling using Inventor CAD software. A detailed 3D design able to visualised a real project and modification can be made before developed a real prototype. The design objectives set out to be achieved were applied to every component, which are durable, stable and easy to use. The main structure is designed to meet the requirement as the central and supporting of the whole weight of the door. It must be sufficiently resistant to be able to logistic the load. Prototype design was first implemented by keeping in mind the safety requirement and the proper clearance of the structure with load from the based. The design of tool should be able to carry various types of door, adjustable, portable, quick set-up and user friendly. The handling process is easier using simple hydraulic system to adjust the door clearance at the bottom part and positioning the door at $90^{\circ}$ steady position as shown in Figure 1. 


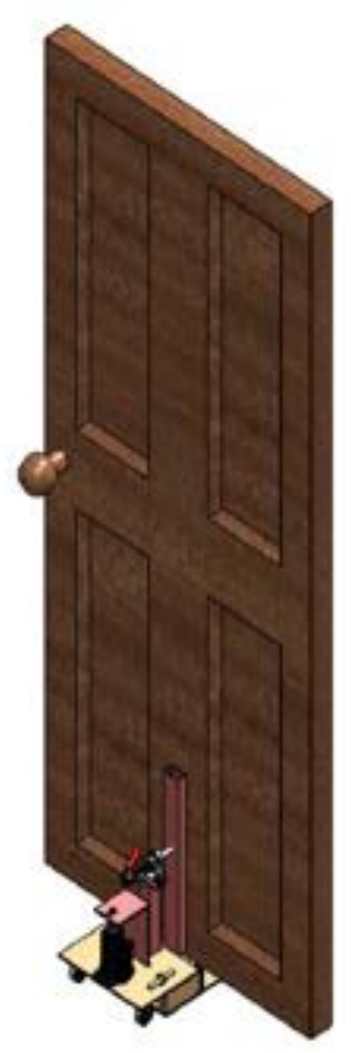

Fig. 1. Prototype with door design

The fabricated multipurpose hydraulic door installation tool is given in Figure 2. The method of using the tool is very simple, starting with adjust at position of the door lifter platform. Next, clamped the door with a clamp that is rubber-padded metal supports to eliminate damage the door surface. Clamps will align with toggle clamp for space adjustment. Then, the hydraulic jack that has been connected to the platform is adjusted to the appropriate height.

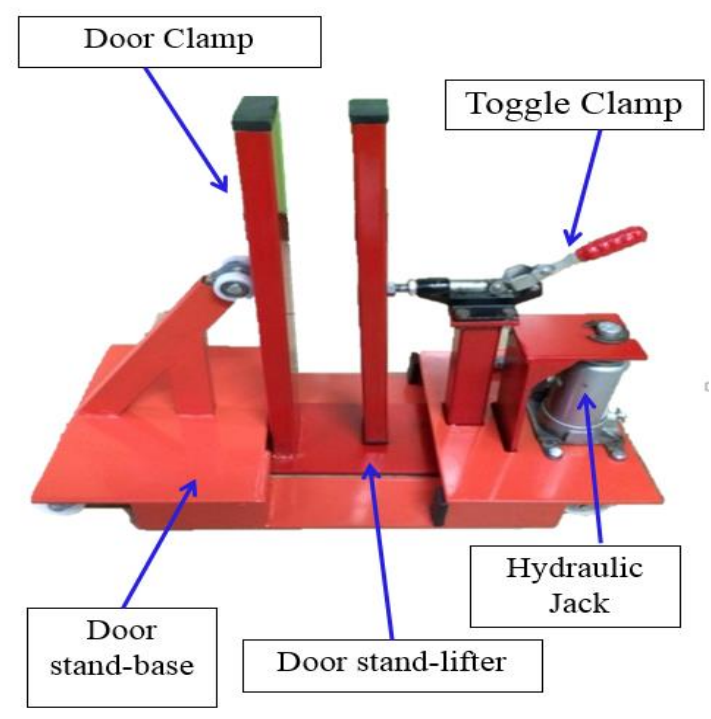

Fig. 2. The multipurpose door installation tool 


\section{Results and Discussion}

This section discusses the findings based on testing on projects that have been conducted. Each method of testing is summarised in Table 1. Table 2 shows testing results comparing process of door installation by manual handling and using jig (Multipurpose Hydraulic Tool).

Table 1

Summary of Testing Methods

\begin{tabular}{l}
\multicolumn{1}{c}{ Testing } \\
\hline 1. Door Installation \\
$\begin{array}{l}\text { The door installation can be made individually. } \\
\text { Easier to setting door in steady } 90 \text { degrees } \\
\text { position and adjusting door clearance. Reduce } \\
\text { the time taken by the employee even though } \\
\text { working alone. }\end{array}$
\end{tabular}

2. Gate Installation

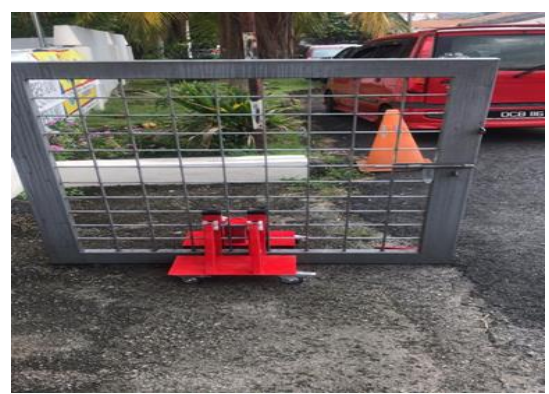

Figure 4 Installation of Gate

3. Transporting purpose

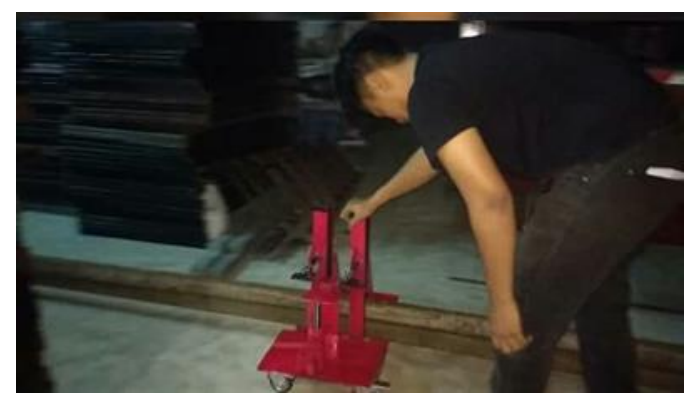

Figure 5 Transporting purpose
The second test is the installation of a fence where the installation of a fence usually requires more than one employee. The tool is capable of holding a fence without support from manpower. The tool able to lifted fence weight over $20 \mathrm{~kg}$

The tool able to transporting heavy item such as tent bar and banquet table which are usually requires at least 2 workers for transporting item. 
Table 2

Testing Results

\begin{tabular}{|c|c|c|c|c|c|}
\hline \multirow[b]{2}{*}{ Type } & \multirow[b]{2}{*}{ Weight } & \multicolumn{2}{|c|}{ Handling } & \multicolumn{2}{|c|}{ Installing Time } \\
\hline & & Manual & $\begin{array}{l}\text { Multipurpose } \\
\text { Installation Jig }\end{array}$ & Manual & $\begin{array}{l}\text { Multipurpose } \\
\text { Installation Jig }\end{array}$ \\
\hline Plastic & $<1 \mathrm{~kg}$ & $\begin{array}{c}\text { Hard } \\
\text { (2 Workers) }\end{array}$ & $\begin{array}{c}\text { Easy } \\
\text { (1 Worker) }\end{array}$ & 3 Minute & 1 Minute \\
\hline Wood & $>5 \mathrm{~kg}$ & $\begin{array}{c}\text { Hard } \\
\text { (3 Workers) }\end{array}$ & $\begin{array}{c}\text { Easy } \\
\text { (1 Worker) }\end{array}$ & 15 Minute & 7 Minute \\
\hline Gate & $>10 \mathrm{KG}$ & $\begin{array}{c}\text { Hard } \\
\text { (4 Workers) }\end{array}$ & $\begin{array}{c}\text { Easy } \\
\text { (2 workers) }\end{array}$ & 25 Minute & 17 Minute \\
\hline
\end{tabular}

\section{Conclusions}

Multipurpose installation jig was successfully achieved the objectives. The purpose of this project is to facilitate users to speed up the installation process. In terms of cost, the project is very affordable and costs can be reduced if the earnings are made on a smaller scale. In terms of quality and quality, the project achieved a satisfactory level due to its manufacturing of steel materials. In terms of maintenance, the project is easy to operate and does not require skilled manpower and skilled workers. Steel is a material that meets the requirements and standards and suitable for installation work. Furthermore, stainless type steel is chosen because of its corrosion-resistant properties are ideal in processing the installation for a long time.

Following the various studies and experiments undertaken on this project, it was found that the use of Multi-purpose installation jig was successful in assisting contractors and also contributing positively to new entrepreneurs. These results can be demonstrated in comparison tables with other methods. Overall, the project has met the project's criteria or objectives as it facilitates and can help the user to install the door in a short time. The system is well accepted as it is easy to operate and maintain this project. Comparison with other methods reinforces the usefulness of this project.

\section{Acknowledgement}

This research was funded by a grant from Ministry of Education of Malaysia (TVET Applied Research Grant Scheme - T-ARGS and its reference number: KPT.JPP.PPPP.700-1 Jld.22 (64)- Prototype Development of Multipurpose Hydraulic Door Installation Tool.

\section{References}

[1] Asada,H and By, A.B., (1985). Proceedings of the 1985 IEEE International Conference on Robotics and Automation: Kinematic of Workpart Fixturing, St. Louis, MO, pp. 337-345 (March 1985) IEEE Computer Society Press, Washington, D.C.

[2] Arkya, D., Chaitanya, V. (2014). Door Installing Fixture of Car for Maintaining Gap and Flushness. International Journal of Scientific \& Engineering Research, Vol. 5(6),752-754.

[3] Kerschbaum, Philipp, Lutz Lorenz, and Klaus Bengler. "A transforming steering wheel for highly automated cars." In 2015 IEEE Intelligent Vehicles Symposium (IV), pp. 1287-1292. IEEE, 2015. https://doi.org/10.1109/IVS.2015.7225893

[4] Tsao, Cynthia CY, Iris D. Tommelein, Eric Swanlund, and Gregory A. Howell. "Case study for work structuring: Installation of metal door frames." In Proc. Eighth Annual Conference of the International Group for Lean Construction, pp. 17-19. 2000.

[5] Tsao, Cynthia CY, and Iris D. Tommelein. "Comparing and implementing alternative work structures: installation of door frames." In CONFERENCE OF THE INTERNATIONAL GROUP FOR LEAN CONSTRUCTION, vol. 10. 2002. 